\title{
تغير المناخ والتنمية البيئية المستدامة في مصر
}

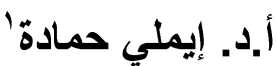

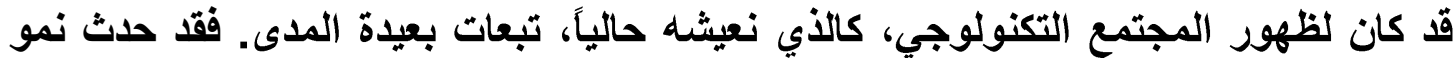

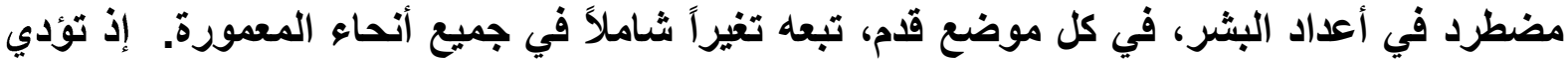

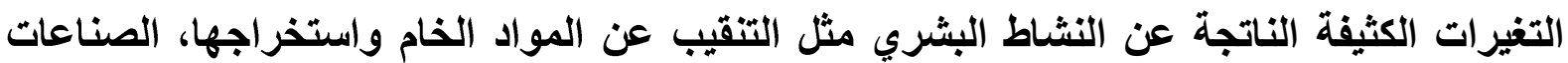

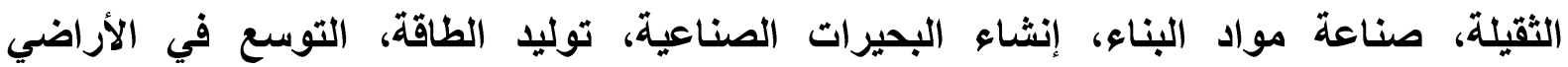

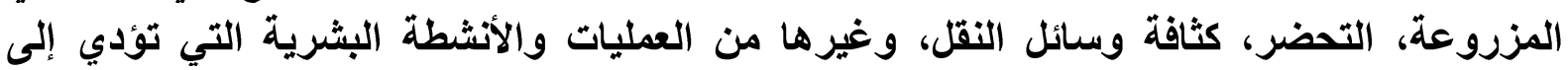
تلوث الهواء وتغيير اللاندسكيب الطبيعي للأرض.

وتعتبر ظاهرة الاحتباس الحراري " الدفء العالمي " أحل مظاهر تغير المناخ كنتيجة مباشرة

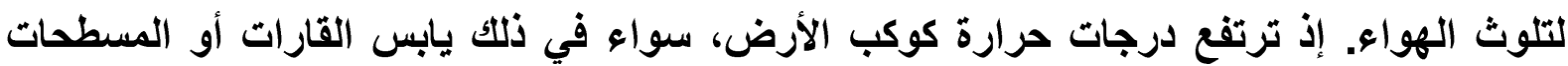

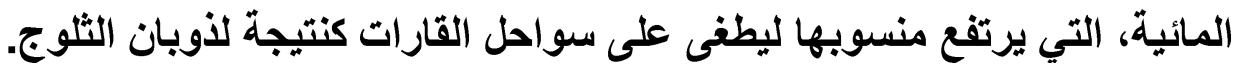

وقد اتفق غالبية علماء المناخ والبيئة على تفاقم خطورة الدفء العالمي. ويقابل هؤلاء إنهاء إنكار

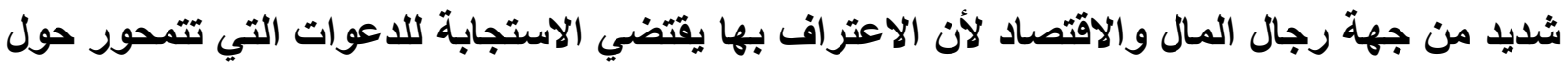

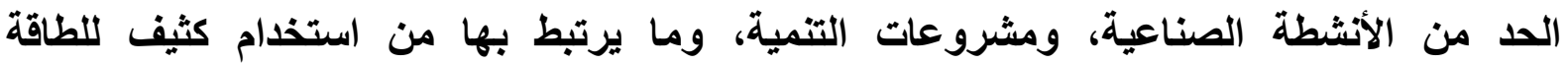
الأحفورية، لتصبح المحصلة خصماً من مكتسباتهم المادية.

وتتعقد المشكلة لاى الحكومات بين طرفين متقابلين، أولهما: مجابهة متطلبات النمو السكاني

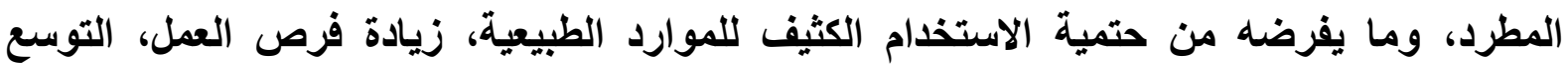

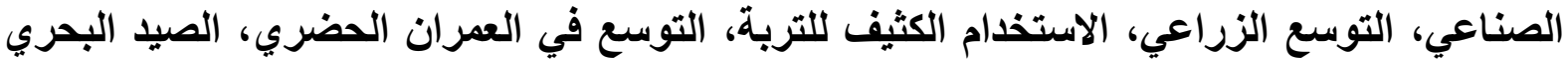

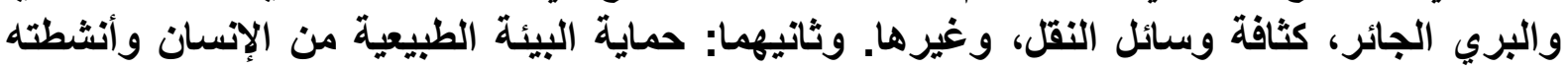

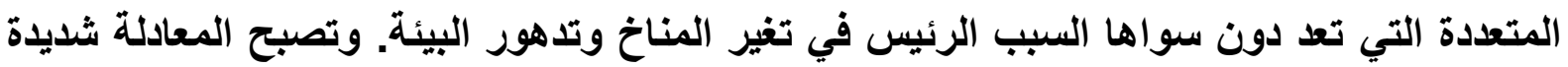

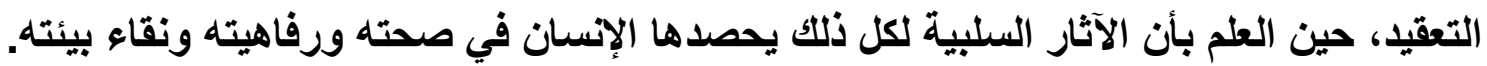

و هكذا، فليس من المستغرب أن تصبح ظاهرة الدفع عالمية تتثارك فيها الدول المتقدمة،

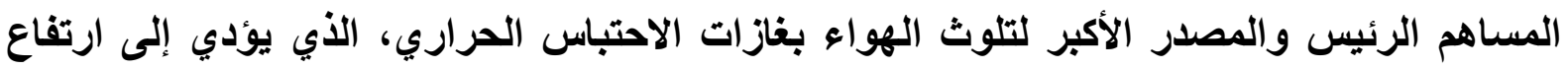

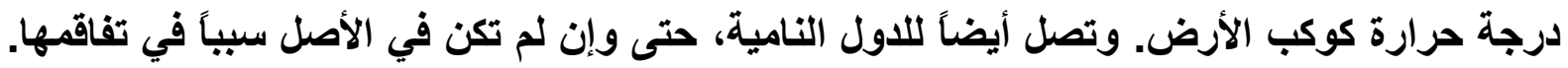

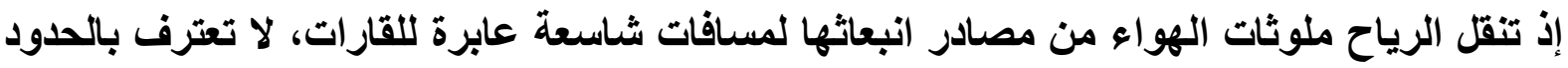
الطبيعية من جبال وأنهار وغير النها، أو حتى الحدود السياسية.

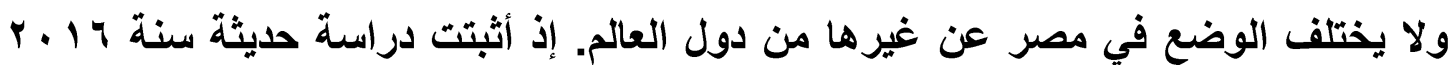

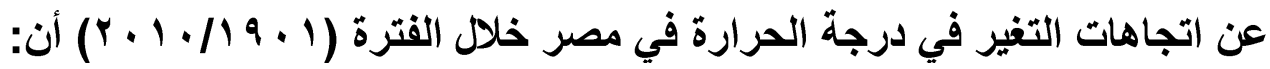


1. المعدل السنوي لارجات الحرارة يتجه نحو الارتفاع ليس فقط خلال القرن الماضي، بل

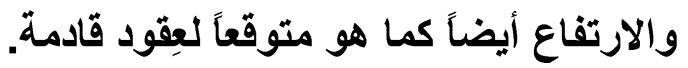

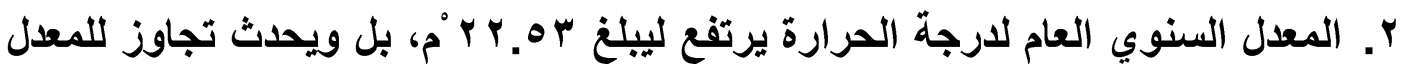
في أكثر من هـ سنة على مدار القرن العشرين.

وينعكس تأثير هذا الارتفاع في درجات الحرارة في مصر على مختلف مناحي الحياة والأنثطة

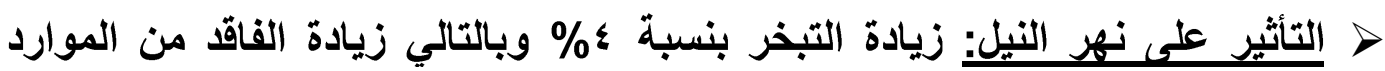

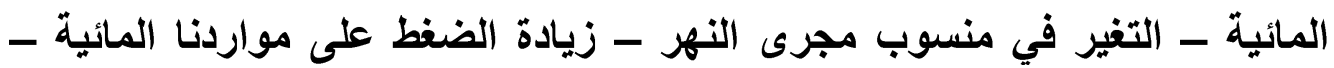
انخفاض نصيب الفرد من المياه

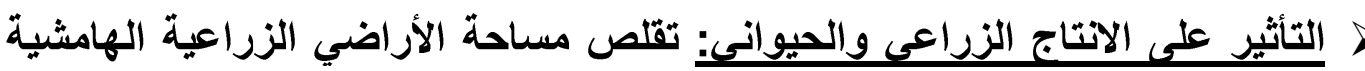

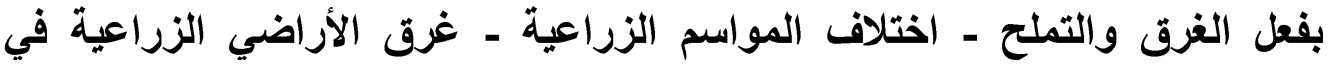

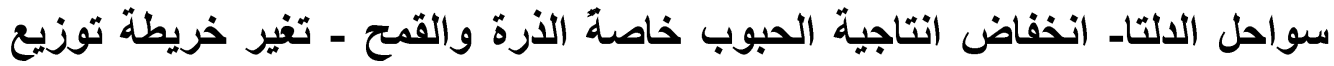

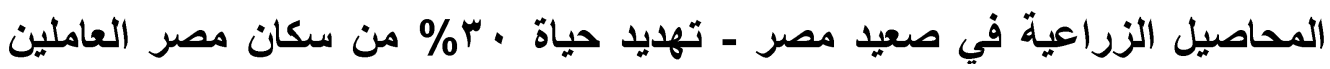
بالقطاع الزراعي الزير

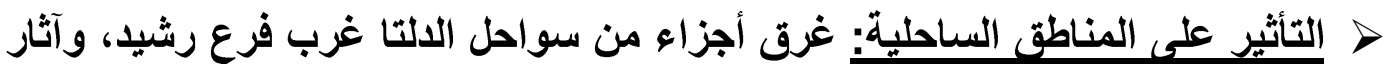

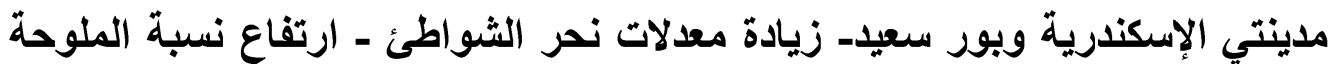

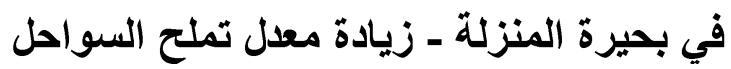

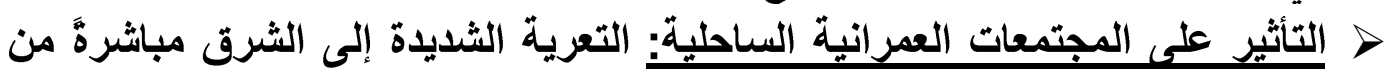

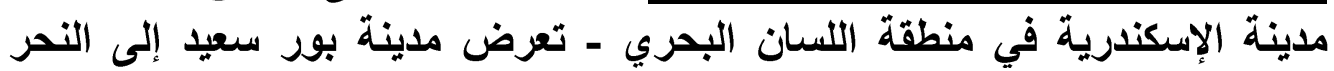

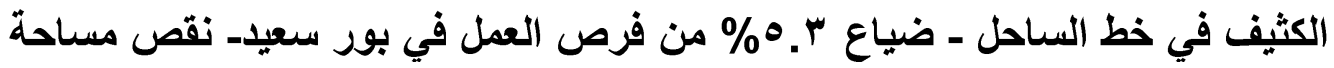

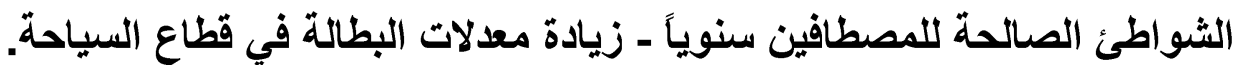

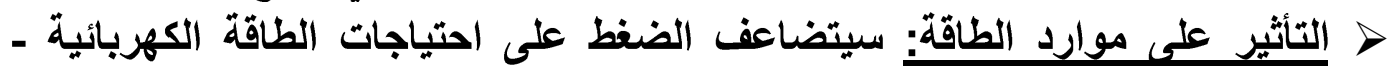

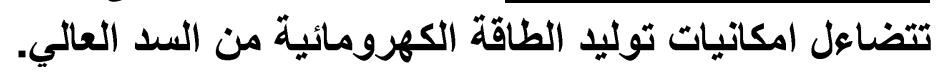
وتسعى الحكومة المصرية لمجابهة الأثار السلبية لتفير المناخ مع تطبيق التنمية المستدامة لتحقيق التوازن المنثود بين صحة البيئة ورفاهية المواطن من خلال:

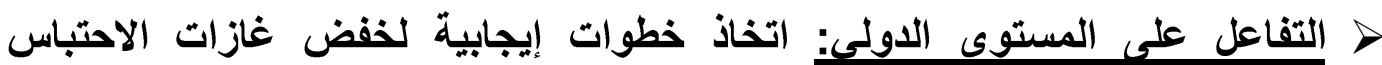
الحراري - توقيع السيد رئيس الجمهورية على اتفاقية تغير المناخ فئن في باريس سنة r. 10 > التفاعل على المستوى الوطنى : زيادة الوعي البيئي - تلعيم مراكز البحث العلمي

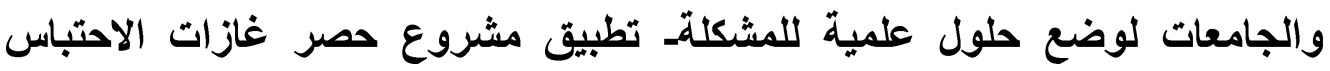

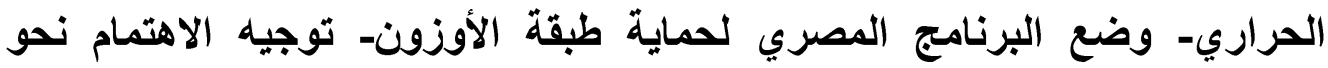

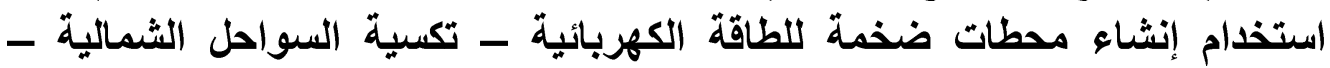

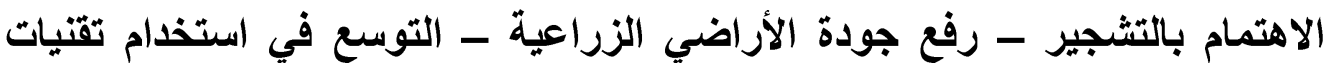

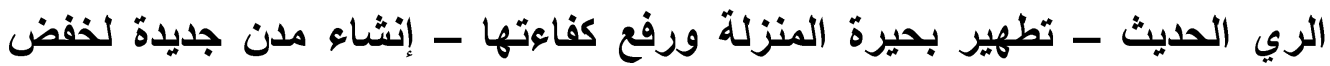

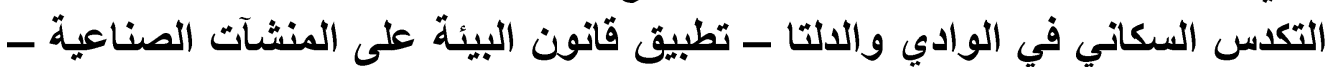




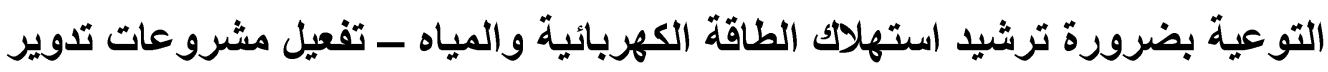

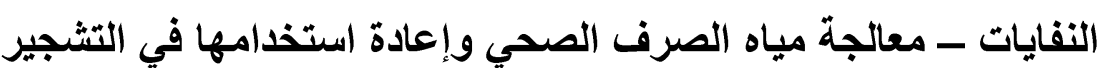

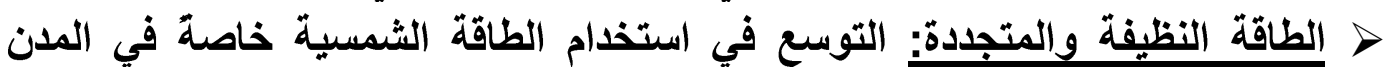

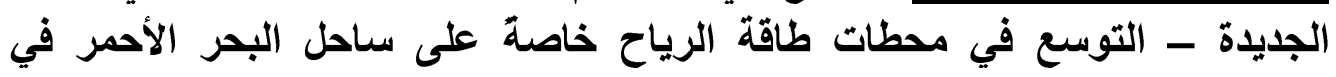

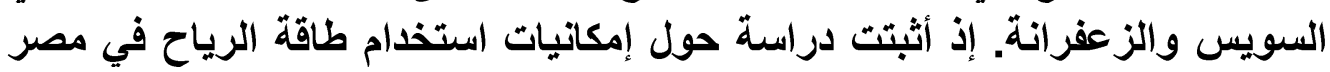

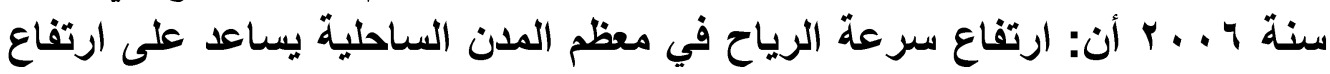

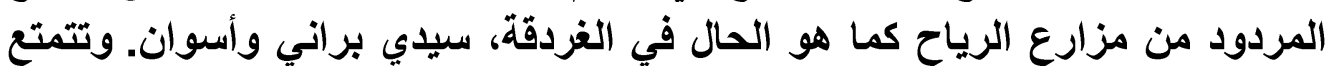

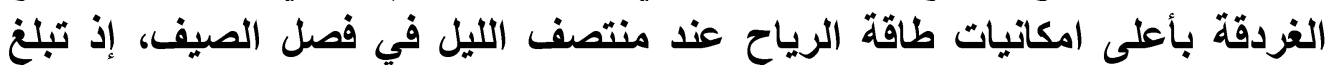

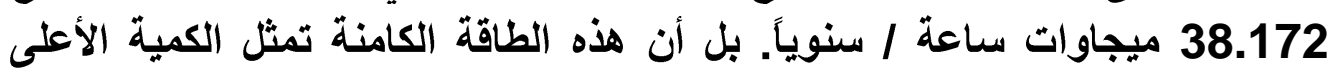
خلال الفصول الأربعة عند منتصف الليل مقارنة بسائر المدن المصرية. 